\title{
Routine use of chest $x$-ray for low-risk patients undergoing a periodic health examination: a retrospective cohort study
}

\author{
Zachary Bouck MPH, Graham Mecredy MSc, Noah M. Ivers MD, Ciara Pendrith MSc, Ben Fine MD SM, \\ Danielle Martin MD, Richard H. Glazier MD, Joshua Tepper MD, Wendy Levinson MD, \\ R. Sacha Bhatia MD MBA
}

\section{Abstract}

Background: Many evidence-based recommendations advocate against the use of routine chest x-rays for asymptomatic, low-risk outpatients; however, it is unclear how regularly chest x-rays are ordered in primary care. Our study aims to describe the frequency of, and variation in, routine chest x-ray use in low-risk outpatients among primary care physicians.

Methods: In this retrospective cohort study, Ontario residents aged 18 years and older with a periodic health examination (PHE) between Apr. 1, 2010, and Mar. 31, 2015, were identified via administrative claims data. Patients with a recent history (last 3 years) of any of the following were excluded: cardiac or pulmonary disease, high-risk comorbidity (e.g., diabetes), consultations/visits or procedures involving cardiac or pulmonary specialists, cancer and severe chest trauma. The primary outcome, a routine chest x-ray, was defined as at least 1 chest $x$-ray claim within 7 days after a PHE.

Results: While a routine chest x-ray followed only $2.42 \%$ of 2847508 PHEs, one-quarter of family physicians (499/2031) ordered chest $\mathrm{x}$-rays for more than $5.0 \%$ of their PHEs (interquartile range $1.5 \%-5.0 \%$ ) and accounted for $62.9 \%$ of all tests observed. Routine chest $\mathrm{x}$-ray use declined by $2.0 \%$ per quarter (adjusted rate ratio $0.98,95 \%$ confidence interval $[\mathrm{Cl}]$ 0.97-0.98). Older age (4564 yr v. 18-44 yr, adjusted odds ratio [OR] 1.82, 95\% Cl 1.78-1.86; $\geq 65$ yr v. 18-44 yr, adjusted OR 2.48, 95\% Cl 2.39-2.58) and male sex of the patient (OR 2.19, 95\% Cl 2.14-2.24) and male sex of the provider (OR 1.55, 95\% Cl 1.51-1.59) were significantly associated with increased odds of a routine chest $x$-ray being ordered.

Interpretation: It is relatively uncommon for a chest x-ray to be ordered as part of a PHE in Ontario; however, the substantial variation observed among physicians suggests potential for interventions targeted at the most frequent users.

hest radiography can assist in the diagnosis and management of cardiac and respiratory disease; however, there are many scenarios in which chest $\mathrm{x}$-rays have low value, as the benefits of testing are unclear or offset by the potential for patient harm. ${ }^{1-4}$ For example, the Canadian Association of Radiologists labels the use of routine chest radiography for a periodic health examination (PHE) - a service involving an outpatient with unremarkable history and physical examination - as not indicated because of low clinical value. ${ }^{4-7}$ As primary care physicians are typically responsible for conducting PHEs, the College of Family Physicians of Canada included routine chest x-rays in their top 13 list, for Choosing Wisely Canada, of low-value tests, treatments and procedures that patients and physicians should question. ${ }^{8}$

The limited utility of routine radiographs may be best evidenced by a cohort study of 1282 primary care outpatients who received a chest $\mathrm{x}$-ray despite the absence of thoracic symptoms. ${ }^{9}$ The authors found that only $1.2 \%$ of chest $\mathrm{x}$-rays detected a major abnormality. Upon further inspection, 93\% of these findings were false positives and none required treatment. ${ }^{9}$ Because of its trivial diagnostic yield and high falsepositive rate, routine chest $\mathrm{x}$-ray for asymptomatic, low-risk outpatients often confers no clinical benefit, while leading to additional unnecessary services (e.g., advanced imaging, procedures and consultations) that can pose additional patient harms and system costs. ${ }^{5-7,9-11}$

Despite extensive evidence against routine chest $\mathrm{x}$-rays for asymptomatic or low-risk outpatients, the frequency with

Competing interests: None declared.

This article has been peer reviewed.

Correspondence to: R. Sacha Bhatia, sacha.bhatia@wchospital.ca CMAJ Open 2018. DOI:10.9778/cmajo.20170138 
which family physicians are ordering these tests as part of a PHE is unknown. We aimed to quantify the frequency of, and variation in, routine chest $\mathrm{x}$-ray use among health regions, practices and individual physicians in Ontario, Canada. Furthermore, we assessed temporal trends in province-wide use and investigated patient- and provider-level characteristics associated with routine chest $\mathrm{x}$-ray use.

\section{Methods}

\section{Setting, study design and data sources}

We conducted a retrospective cohort study in Ontario, Canada, between fiscal years 2010 and 2014, using population-based administrative health care databases. The data sets were linked using unique encoded identifiers and analyzed at the Institute for Clinical Evaluative Sciences (ICES). The Ontario Health Insurance Plan (OHIP) claims database contains all billing claims made by Ontario physicians, whose demographic information is captured in the ICES Physician Database. The Registered Persons Database contains demographic information on all Ontario residents eligible for OHIP coverage. Client Agency Program Enrolment (CAPE) tables were cross-referenced with OHIP claims to identify patients rostered to primary care physicians, as well as groups of 3 or more physicians who submitted joint billing to the Ontario Ministry of Health and Long-Term Care (herein referred to as a practice). ${ }^{12-14}$ The Discharge Abstract Database and National Ambulatory Care Reporting System contain inpatient hospitalization and emergency department visit records, respectively, which are both coded using the enhanced Canadian version of the International Statistical Classification of Diseases and Related Health Problems, 10th revision (ICD10-CA), and the Canadian Classification of Health Interventions (CCI) coding systems.

\section{Cohort selection}

Our cohort consisted of Ontario residents age 18 years and older with a valid provincial OHIP number who had at least $1 \mathrm{PHE}$ - an annual health examination (A003 with diagnostic code 917) or periodic health visit (K131 or K132) — with a family physician between Apr. 1, 2010, and Mar. 24, 2015. ${ }^{12,15,16}$ These codes are representative of a PHE, as they describe screening and prevention services performed on patients without apparent medical problems on the basis of history or examination. ${ }^{12,15,16}$ The K131 and K132 codes were introduced in January 2013 to provide a more flexible alternative to the annual health examination with the expressed intention of reducing low-value examinations and tests. ${ }^{11,16-19}$ We included $1 \mathrm{PHE}$ per patient per quarter within the observation window; ${ }^{20}$ however, OHIP guidelines limit reimbursement beyond 1 PHE per patient per 12 months per physician. ${ }^{16} \mathrm{We}$ excluded patients with incomplete demographic information and long-term care residents. ${ }^{12}$

Additional exclusions were created by adapting the Canadian Association of Radiologists' standards and referral guidelines for chest radiography (specifically the cardiovascular, thoracic, cancer and trauma sections) to identify clinical scenarios in which the Canadian Association of Radiologists states that chest $\mathrm{x}$-ray investigations are indicated (i.e., most likely to contribute to diagnosis or management). ${ }^{4,6,17}$ We subsequently excluded patients with any of the following documented indications: signs/symptoms (e.g., dyspnea) or prior diagnosis of cardiac or respiratory disease; prior cardiac or thoracic surgery (e.g., aortic valve replacement); cancer diagnosis; or severe thoracic trauma or injury (e.g., pneumothorax). ${ }^{4,17}$ Patients with a high-risk comorbidity diagnosis (e.g., HIV/AIDS) or a prior consultation with a cardiac or respiratory disease specialist were also excluded..$^{10,12,21,22}$ All exclusions, detailed in Appendix 1.1 (Appendix 1, available at www. cmajopen.ca/content/6/3/322/suppl/DC1), were applied using a 3 -year lookback window from the index PHE.

\section{Routine use of chest x-ray}

Our primary outcome was receipt of at least 1 chest $\mathrm{x}$-ray within 7 days after a PHE, assessed using OHIP claims. ${ }^{4,12}$ We excluded chest $\mathrm{x}$-rays that could not be linked to the physician who conducted the PHE or those performed during an emergency department visit or hospital admission (Appendix 1.2 [Appendix 1]). Concurrent with the 2013 PHE billing changes, the OHIP Schedule of Benefits added statements against the reimbursement of routine chest $\mathrm{x}$-ray including investigations done as part of a PHE. ${ }^{11,16-18}$

We chose a short observation window to increase the likelihood an observed chest $\mathrm{x}$-ray was ordered as part of a PHE. A preliminary analysis supported a 7-day window by revealing that the majority of chest $\mathrm{x}$-ray claims within 30 days after a PHE (70.4\%) occurred within the first week (Appendix 1.3 [Appendix 1]).

\section{Covariates}

Time was compartmentalized into 20 quarters within our study window. We also captured patient-, physician- and practice-level characteristics that have been previously associated with receipt of low-value care (Appendix 1.4 [Appendix 1]). ${ }^{12,23}$ Demographic data were collected on both patients (age, sex, rurality) and physicians (sex, years since graduation, international medical graduate status). ${ }^{12,23}$ Patients' socioeconomic status was approximated via quintiles of median neighbourhood income. ${ }^{24}$ Patients with a hospital admission for a non-cardiopulmonary reason within the past 5 years were identified. ${ }^{12}$ Patient history of dementia and rheumatologic disease within the past 5 years, as well as receipt of any mental health care in the past year, was also noted. ${ }^{12}$ Payment model was recorded per practice. ${ }^{12}$

\section{Statistical analysis}

Routine chest $\mathrm{x}$-ray rates were calculated over time (by quarter) and by region (local health integration network [LHIN]), practice and physician. Variation was assessed via interquartile ranges (IQR) and coefficients of quartile deviation $([\mathrm{Q} 3-\mathrm{Q} 1] /[\mathrm{Q} 3+\mathrm{Q} 1]) \cdot{ }^{12,25}$

Temporal trends in routine chest $\mathrm{x}$-ray use were analyzed via negative binomial regression with the number of routine chest $\mathrm{x}$-rays as the dependent variable, quarter as a continuous 
independent variable and the log number of PHE as an offset term. To account for seasonality, 3 indicator variables were created to represent the quarter in which a PHE occurred irrespective of fiscal year. Rate ratios with $95 \%$ confidence intervals (CIs) were calculated to assess the effect of explanatory variables on chest $\mathrm{x}$-ray use. Total PHE billing volume over time was independently analyzed via negative binomial regression. Utilization was modelled rather than associated cost, as Choosing Wisely Canada's primary focus is on reducing the frequency of potentially harmful low-value care rather than cost savings. ${ }^{26}$

Mixed-effects logistic regression was used to analyze patients' odds of having a routine chest $\mathrm{x}$-ray while adjusting for all covariates detailed in the preceding section. Fixed effects were expressed via odds ratios (ORs) with 95\% CIs. Random intercepts, included to account for within-practice correlation, enabled calculation of the median OR - a measure of practice-level variation in the outcome adjusted for all other factors in the model - and the intraclass correlation coefficient. ${ }^{27-29}$ If one were to calculate the OR for each pair of patients with the same covariates from different practices, while always placing the patient at higher risk in the numerator $(\mathrm{OR} \geq 1)$, the median of the resulting $\mathrm{OR}$ distribution is the median OR. ${ }^{27-29}$ The median OR is directly comparable to a fixed-effect OR. ${ }^{27-29}$ For example, a median OR of 1.50 suggests that, in the median case, a patient has
$50 \%$ higher odds of having a routine chest $\mathrm{x}$-ray if their examination occurs at one randomly selected practice versus another. ${ }^{27}$ Only PHEs involving a patient linked to an identifiable family physician and practice were included in the regression sample. We were unable to model physicianspecific intercepts and repeated, patient-level measures with random effects because of computational issues. We randomly sampled $1 \mathrm{PHE}$ per patient to facilitate convergence without introducing temporal bias. ${ }^{30}$

All analyses were performed using SAS version 9.4 (SAS Institute) at a significance level of $p \leq 0.05$.

\section{Ethics approval}

The use of data in this project was authorized under section 45 of Ontario's Personal Health Information Protection Act, which does not require review by a research ethics board.

\section{Results}

\section{Cohort characteristics by routine chest x-ray status}

The resulting cohort consisted of 2847508 PHEs conducted on 1819696 Ontario outpatients age 18 years and older who were assumed to be asymptomatic and at low risk for cardiac and respiratory disease (Figure 1). In total, $2.42 \%$ of the PHEs resulted in the examined patient having a chest $\mathrm{x}$-ray that was ordered by the attending family physician.

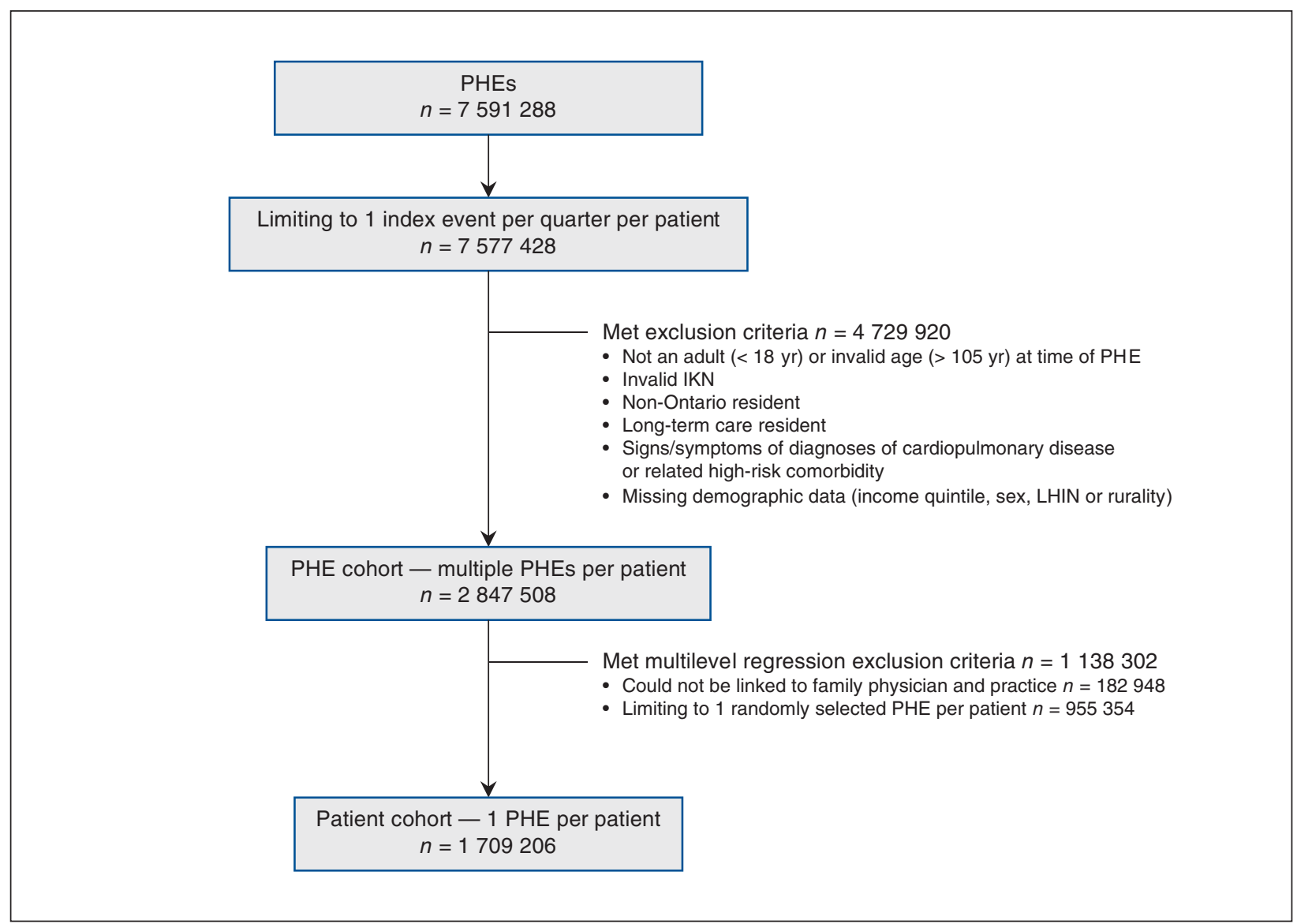

Figure 1: Cohort creation. Note: IKN = ICES key number, LHIN = local health integration network, PHE = periodic health examination. 


\begin{tabular}{|c|c|c|}
\hline Characteristic ${ }^{*}$ & $\begin{array}{c}\text { No. (\%) with CXR } \\
n=68848\end{array}$ & $\begin{array}{c}\text { No. (\%) without CXR } \\
\quad n=2778660\end{array}$ \\
\hline \multicolumn{3}{|l|}{ Patient level } \\
\hline \multicolumn{3}{|l|}{ Age, yr } \\
\hline Mean $(95 \% \mathrm{Cl})$ & $46.4(46.3-46.5)$ & $42.1(42.1-42.1)$ \\
\hline $18-44$ & $29542(42.9)$ & $1585698(57.1)$ \\
\hline $45-64$ & 32771 (47.6) & $1023450(36.8)$ \\
\hline$\geq 65$ & $6535(9.5)$ & $169512(6.1)$ \\
\hline \multicolumn{3}{|l|}{ Sex } \\
\hline Female & $26198(38.1)$ & $1735658(62.5)$ \\
\hline Male & $42650(61.9)$ & $1043002(37.5)$ \\
\hline \multicolumn{3}{|l|}{ Rurality } \\
\hline Rural & $3775(5.5)$ & 212201 (7.6) \\
\hline Non-rural & $65073(94.5)$ & 2566459 (92.4) \\
\hline \multicolumn{3}{|l|}{ Neighbourhood income quintile } \\
\hline 1 (lowest) & $13498(19.6)$ & 414265 (14.9) \\
\hline 2 & $15209(22.1)$ & $502926(18.1)$ \\
\hline 3 & $13844(20.1)$ & $560390(20.2)$ \\
\hline 4 & $14247(20.7)$ & $642577(23.1)$ \\
\hline 5 (highest) & $12050(17.5)$ & $658502(23.7)$ \\
\hline Hospital admission - past $5 \mathrm{yr}$ & $4486(6.5)$ & 312444 (11.2) \\
\hline Mental health care - past yr & $7012(10.2)$ & $339760(12.2)$ \\
\hline Dementia - past $5 \mathrm{yr}$ & $284(0.4)$ & $8920(0.3)$ \\
\hline Rheumatologic disease - past $5 \mathrm{yr}$ & $3449(5.0)$ & $116576(4.2)$ \\
\hline \multicolumn{3}{|l|}{ Rostered to primary care physiciant } \\
\hline Yes & 68822 (> 99.9) & $2777436(>99.9)$ \\
\hline No & $26(<0.1)$ & $1224(<0.1)$ \\
\hline \multicolumn{3}{|l|}{ Physician levelł } \\
\hline \multicolumn{3}{|l|}{ Sex } \\
\hline Female & $15952(23.2)$ & $1243246(44.9)$ \\
\hline Male & $52678(76.8)$ & $1526081(55.1)$ \\
\hline IMG & 22689 (33.1) & $824840(29.8)$ \\
\hline $\begin{array}{l}\text { Years since graduation, } \\
\text { mean }(95 \% \mathrm{Cl})\end{array}$ & $28.8(28.7-28.9)$ & $24.2(24.2-24.2)$ \\
\hline \multicolumn{3}{|l|}{ Practice level } \\
\hline \multicolumn{3}{|l|}{ Primary care practice model§ } \\
\hline Fee-for-service & $13891(20.2)$ & $422355(15.3)$ \\
\hline Family health group & $29594(43.1)$ & $995071(35.9)$ \\
\hline Family health network & $110(0.2)$ & $8548(0.3)$ \\
\hline Family health organization & $10709(15.6)$ & $656365(23.7)$ \\
\hline Family health team & $8371(12.2)$ & $558228(20.2)$ \\
\hline Other & $5955(8.7)$ & $128760(4.6)$ \\
\hline
\end{tabular}

Note: $\mathrm{Cl}=$ confidence interval, $\mathrm{CXR}=$ chest $\mathrm{x}$-ray, IMG = international medical graduate. ${ }^{*}$ For all characteristics (except rostered to primary care physician), $p<0.001$ across groups defined by post-physcial health examination CXR receipt status. $p$ values not adjusted for potential intra-practice correlation.

tVariable indicates whether patients were rostered to a primary care physician at study entry. ¥Provider-level variables only available for those index events involving a patient rostered to a primary care physician with a reported physician number for linkage $(n=2837957)$. $\S$ Represents the primary care patient enrollment model that informs practice organization and remuneration.
Patient, physician and practice characteristics for all eligible examinations are detailed in Table 1 . In general, examinations followed by a routine chest $\mathrm{x}$-ray involved older, male patients and male physicians further removed from graduation.

\section{Variation by health region, practice and physician}

Our sample consisted of 22.6\% (2031/8992) of all family physicians in Ontario during the study period. Ordering variation was more pronounced among the 2031 physicians (range $0.3 \%-70.8 \%$, interquartile range [IQR] $1.5 \%-5.0 \%$, coefficient of quartile deviation 0.54 ) than among the 677 practices (IQR $0.9 \%-$ $2.3 \%$, coefficient of quartile deviation 0.44 ) or 14 LHINs (IQR $1.9 \%-2.9 \%$, coefficient of quartile deviation 0.20) (Supplemental Figures 1 and 2 [Appendices 2 and 3 , available at www.cmajopen.ca/content/6/3/E322/ suppl/DC1]). One-quarter of family physicians (499/2031) ordered chest $\mathrm{x}$-rays for more than $5.0 \%$ of their PHEs (interquartile range $1.5 \%-5.0 \%$ ). Figure 2 shows the number of physicians by chest $\mathrm{x}$-ray ordering rate quartile. Physicians in the top quartile by ordering rate accounted for $62.9 \%$ of all tests observed.

\section{Variation over time}

Figure 3 demonstrates declining use of routine chest $\mathrm{x}$-rays and PHEs over the study period. Routine chest $\mathrm{x}$-ray use dropped 1.0\% between Apr. 1, 2010 (3.0\%), and Mar. 31, 2015 (2.0\%) (IQR 2.0\%-2.8\%, coefficient of quartile deviation 0.16). Supplemental Table 1 [Appendix 4, available at www.cmajopen.ca/content /6/3/E322/suppl/DC1] shows that, on average, routine chest $\mathrm{x}$-ray use decreased by $2.0 \%$ per quarter in Ontario (rate ratio $0.98,95 \%$ CI $0.97-0.98$ ). Use was significantly higher in January to March than in any other quarter, irrespective of fiscal year. Figure 3 depicts lower total PHE volumes from 2013 onward. Total PHE volume decreased, on average, by $2.0 \%$ per quarter (rate ratio $0.98,95 \%$ CI $0.97-0.98$ ).

\section{Factors associated with routine chest x-ray use}

Our final mixed-effects logistic regression model is presented in Table 2. Older adults, men and those in the lowest income quintile had increased odds of having a routine chest $\mathrm{x}$-rays Male physicians and physicians further removed from graduation had increased odds of ordering a routine chest $\mathrm{x}$-ray. The degree of interpractice variation was significant as, in the median case, the odds of a patient having a routine chest $x$-ray at one randomly selected high-risk practice were $91 \%$ greater than those of a patient with the same covariates at a randomly selected low-risk practice (median odds ratio [OR] 1.91, 95\% CI 1.86-1.96). Practice-level clustering accounted for $12.3 \%$ of the total variation in routine chest $\mathrm{x}$-ray use. The results of a sensitivity analysis with same-day chest $\mathrm{x}$-ray receipt as the dependent variable 


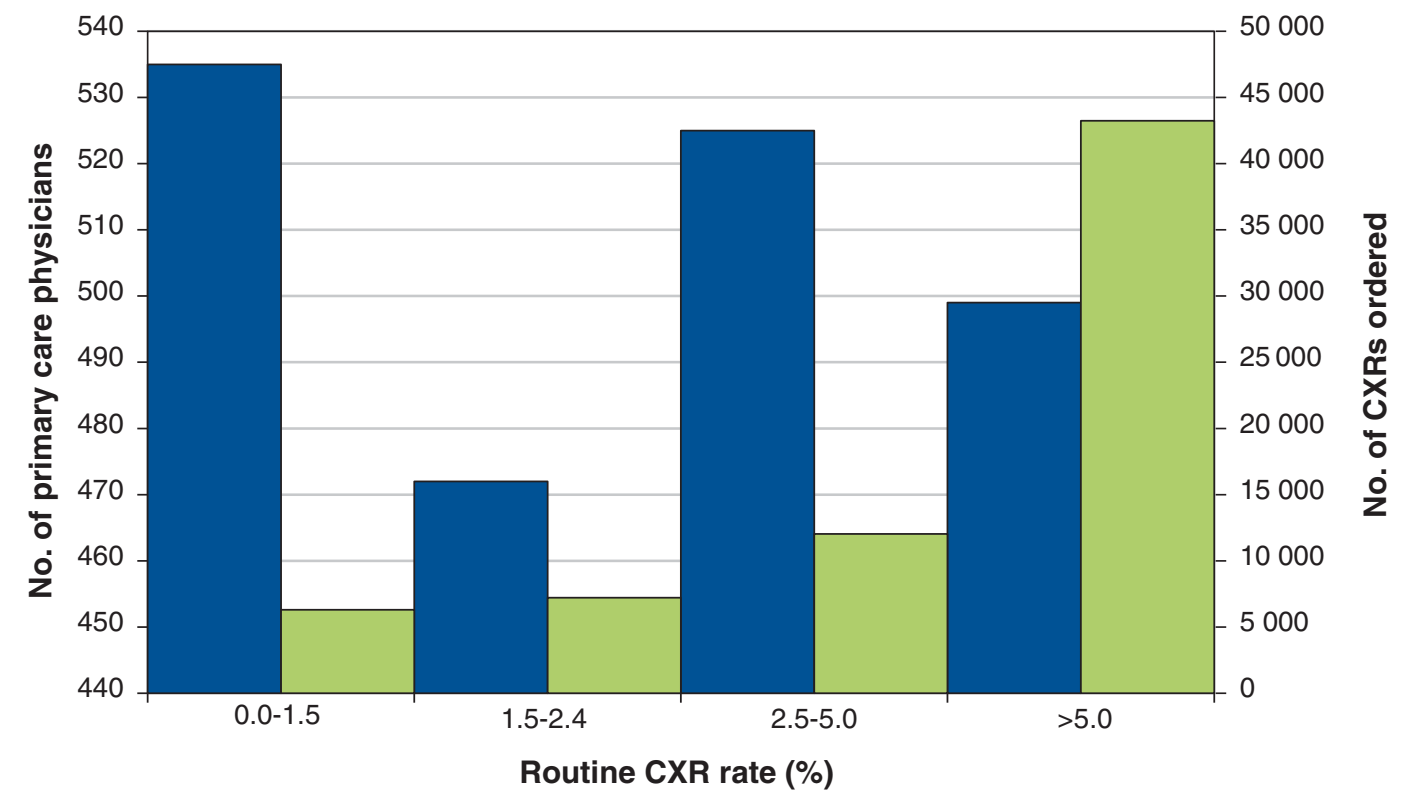

Primary care physicians $\square$ CXRs ordered

Figure 2: Frequency distribution of family physicians in Ontario according to their routine chest $\mathrm{x}$-ray (CXR) ordering rate with corresponding total volume of CXR ordered per rate-based quartile from 2010/11 to 2014/15. Note that the $x$-axis is divided into quartiles based on physician CXR ordering rate.

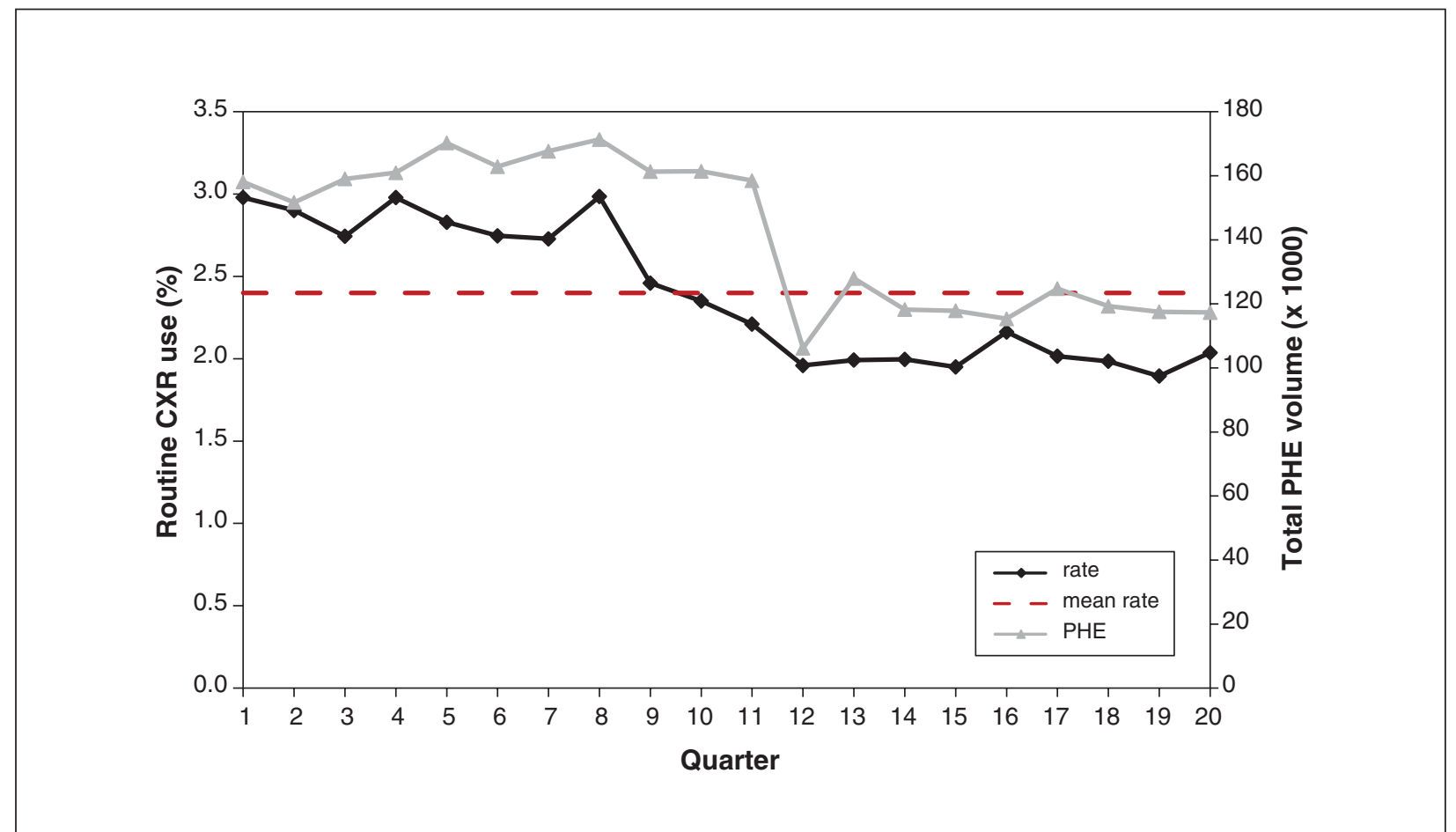

Figure 3: Routine chest x-ray (CXR) ordering rates in Ontario over time, from Apr. 1, 2010, to Mar. 31, 2015. Note that the hatched, horizontal line represents the overall mean rate. Note: $\mathrm{PHE}=$ periodic health examination. 
Table 2: Factors associated with having a routine chest $\mathrm{x}$-ray based on a mixed-effects logistic regression model, $n=1709206$

\section{Fixed effects} $\mathrm{OR}^{*}(95 \% \mathrm{Cl})$

\section{Time-based variables}

\begin{tabular}{|ll|}
\hline Time (fiscal quarter) & $0.98(0.98-0.98)$ \\
\hline April-June v. January-March & $0.92(0.88-0.96)$ \\
\hline July-September v. January-March & $0.91(0.88-0.95)$ \\
\hline October-November v. January-March & $0.90(0.86-0.93)$ \\
\hline
\end{tabular}

Patient characteristics

Age, yr

\begin{tabular}{|lc|}
\hline $45-64$ v. $18-44$ & $1.82(1.78-1.86)$ \\
\hline$\geq 65$ v. $18-44$ & $2.48(2.39-2.58)$ \\
\hline Male & $2.19(2.14-2.24)$ \\
\hline Rural & $1.00(0.95-1.05)$ \\
\hline
\end{tabular}

Neighbourhood income quintile

\begin{tabular}{|lc|}
\hline 2 v. 1 (lowest) & $0.94(0.91-0.97)$ \\
\hline 3 v. 1 (lowest) & $0.85(0.82-0.87)$ \\
\hline 4 v. 1 (lowest) & $0.82(0.79-0.85)$ \\
\hline 5 v. 1 (lowest) & $0.71(0.69-0.74)$ \\
\hline Hospitalization - past $5 \mathrm{yr}$ & $0.89(0.85-0.93)$ \\
\hline Mental health diagnosis - past 5 yr & $0.89(0.86-0.92)$ \\
\hline Dementia diagnosis - past $5 \mathrm{yr}$ & $1.19(1.01-1.39)$ \\
\hline Rheumatologic disease diagnosis - past $5 \mathrm{yr}$ & $1.02(0.97-1.07)$ \\
\hline
\end{tabular}

Physician characteristics

\begin{tabular}{|lc|} 
Male & $1.55(1.51-1.59)$ \\
\hline IMG & $1.01(0.98-1.03)$ \\
\hline Years since graduation & \\
\hline $21-30$ v. $\leq 20$ & $1.21(1.17-1.24)$ \\
\hline$>30$ v. $\leq 20$ & $1.63(1.59-1.68)$ \\
\hline
\end{tabular}

\section{Practice characteristics}

Primary care practice model†

Family health group v. FFS

$0.92(0.89-0.96)$

Family health network v. FFS

$0.73(0.51-1.03)$

Family health organization v. FFS

$0.81(0.77-0.86)$

Family health team v. FFS

$0.87(0.82-0.93)$

Other v. FFS

$1.20(1.09-1.31)$

\section{Random effectsł}

Variance (SE)

$0.46(0.03)$

MOR $(95 \% \mathrm{Cl})$ $1.91(1.86-1.96)$

ICC,§ \%

Note: $\mathrm{Cl}=$ confidence interval, $\mathrm{CXR}=$ chest $\mathrm{x}$-ray, $\mathrm{FFS}$ = fee-for-service, ICC = intraclass correlation coefficient, IMG = international medical graduate, MOR median odds ratio, $\mathrm{OR}=$ odds ratio, $\mathrm{SE}=$ standard error. All reported values based on SAS PROC GLIMMIX output; model estimation method = RSPL;

denominator degrees of freedom estimation method $=$ between and within (bw); covariance structure $=$ standard variance $(\mathrm{vc})$.

${ }^{*}$ Adjusted for all other factors present in the model/table.

tRepresents the primary care patient enrollment model that informs practice organization and remuneration.

$\ddagger$ Estimated based on the distribution of random, practice-specific intercepts. $\S$ Calculated using the linear threshold approach. did not differ substantially from the main analysis (Supplemental Table 2, Appendix 4).

\section{Interpretation}

In this large, retrospective cohort study, we found that routine chest $\mathrm{x}$-rays are infrequently ordered for low-risk outpatients as part of a PHE in Ontario. Among the 2847508 PHEs conducted on 1819696 presumably asymptomatic, low-risk outpatients, only $2.4 \%$ were followed by a chest $\mathrm{x}$-ray. While province-wide use was low, substantial ordering variation was observed across regions and practices and, most notably, between individual family physicians. For example, the top $25 \%$ of physicians by routine chest $\mathrm{x}$-ray use ordered a potentially low-value chest $x$-ray following more than $5 \%$ of their PHEs with a low-risk patient and accounted for $62.9 \%$ of total test volume, whereas the bottom $25 \%$ of physicians ordered a chest $\mathrm{x}$-ray at most $1.5 \%$ of the time and accounted for less than $10 \%$ of tests observed. Furthermore, we observed a significant decline in routine chest $\mathrm{x}$-ray use over time, with rates highest between January and March within any given year.

Previous literature has suggested that despite low clinical value, routine chest $\mathrm{x}$-ray use for asymptomatic and/or lowrisk outpatients in primary care may be quite common. In their review of radiograph reports, Tigges and colleagues found that $34 \%$ of chest $\mathrm{x}$-rays ordered were for "routine or screening purposes"; however, this study was limited to a single primary care centre in the United States. ${ }^{9}$ Conversely, our study involved a large cohort of patients from multiple regions and practices across Ontario and suggests routine chest $\mathrm{x}$-ray use is uncommon in Canada. In fact, routine chest $\mathrm{x}$-ray use appears to be appreciably less common than other forms of low-value imaging we have previously studied..$^{12,23,31}$ Our study underscores the importance of establishing baseline estimates to compare frequency of use across different tests and clinical scenarios, which can provide health care decisionmakers with a basis for determining which tests they might preferentially target with quality improvement initiatives aimed at reducing low-value care..$^{32}$

The observed decline in routine chest $\mathrm{x}$-ray use over time may be due to increased recognition among physicians of the limited utility of chest $\mathrm{x}$-rays for screening asymptomatic, low-risk patients, possibly promoted by 2013 OHIP Schedule of Benefits revisions that included recommendations against routine chest $\mathrm{x}$-ray reimbursement and new PHE codes to reduce low-value testing. However, it appears the downward trend in chest $\mathrm{x}$-ray use was initiated before the announcement of OHIP Schedule changes in November 2012 and their subsequent implementation in January 2013., ${ }^{4,5,11,16-18}$ Further research to identify unmeasured factors that may explain the precipitous drop in chest x-ray use from January-March 2012 to April-June 2012 is warranted.

Substantial variation among regions, practices and individual primary care physicians was observed, which is consistent with previous research. ${ }^{12,22,23,31,32}$ Significant within-practice variation in having a post-PHE chest $\mathrm{x}$-ray persisted even after we adjusted for several patient and physician characteristics, 
suggesting that unmeasured practice-level characteristics account for a sizeable portion of the observed variability in routine chest $\mathrm{x}$-ray use. Patients who were older and male were more likely to have a routine chest $\mathrm{x}$-ray. Male physicians and those further removed from their medical school graduation were more likely to order routine chest $\mathrm{x}$-rays. These same characteristics have previously been associated with routine electrocardiography (ECG) use in low-risk outpatients. ${ }^{11}$ Identification of common factors for ordering low-value care across tests could inform development of interventions that may effectively curb use of several low-value services. Furthermore, future investigations might consider estimating physician-specific ordering rates for multiple low-value tests (e.g., ECG and chest $x$-ray) that may result from a PHE to create a broader, more robust profile of care per physician..$^{12,33}$

\section{Limitations}

Several methodological limitations are worth noting. Administrative, claims-based data do not provide all of the clinical information available to the physician in making their decision to order or withhold a test, such as symptoms or risk factors presented via physical exam or patient history. ${ }^{33}$ For example, our data do not capture smoking or alcohol use, known risk factors for cardiac and respiratory disease that may indicate a chest $\mathrm{x}$-ray investigation. ${ }^{10}$ Without this information, it is possible that patients or chest $\mathrm{x}$-rays may have been misclassified as low-risk or low-value, respectively, resulting in inaccurate estimates of overuse via denominator and/or numerator inflation. ${ }^{4,10} \mathrm{We}$ hope that our application of an extensive list of risk-based exclusion criteria mitigated the extent of misclassification. ${ }^{12,15,16}$ The omission of unmeasured risk factors from regression may also bias OR estimates where the measured covariate and unmeasured risk factor are significantly correlated. The direction of bias would correspond with the direction of this correlation. ${ }^{34}$ In addition, the accuracy of the algorithms used to rule in patients and tests has not been previously validated by independent studies. Lastly, our findings may not be generalizable to other provinces and territories, as PHEs are not standardized across Canada and may target broader patient populations or entail different services in other jurisdictions. ${ }^{7}$

\section{Conclusion}

It appears that Ontario family physicians are adhering to guidelines and recommendations by ordering routine chest $\mathrm{x}$-rays at a low frequency for PHEs with an asymptomatic or low-risk outpatient. Further research exploring the causes of variation in physician ordering practices, particularly among high-ordering physicians, is warranted.

\section{References}

1. Institute of Medicine (US) Committee on Quality of Health Care in America. Crossing the quality chasm: a new bealth system for the 21st century. Washington: National Academy Press; 2001.

2. Wennberg JE, Fisher ES, Skinner JS. Geography and the debate over Medicare reform. Health Aff (Millwood) 2002;(Suppl Web Exclusives):W96-114.

3. Levinson W, Kallewaard M, Bhatia RS, et al.; Choosing Wisely International Working Group. 'Choosing Wisely': a growing international campaign. BMF Qual Saf 2015;24:167-74.
4. Coblentz CL, Matzinger F, Samson LM, et al. CAR standards for chest radiography. Ottawa: Canadian Association of Radiologists; 2000.

5. Expert Panel on Thoracic Imaging; McComb BL, Chung JH, Crabtree TD, et al. ACR Appropriateness Criteria ${ }^{\circledR}$ routine chest radiography. 7 Thorac Imaging 2016;31:W13-5.

6. Fine B, Dhanoa D. Imaging appropriateness criteria - why Canadian family physicians should care. Can Fam Physician 2014;60:217-8.

7. Annual physical examination practices by province/territory in Canada. Mississauga $(\mathrm{ON})$ : The College of Family Physicians of Canada; 2013. Available: www.cfpc. ca/uploadedFiles/Health_Policy/CFPC_Policy_Papers_and_Endorsements/ CFPC_Policy_Papers/CFPC\%20PT\%20Annual\%20Exam.pdf (accessed 2017 Apr. 24).

8. College of Family Physicians of Canada. Thirteen things physicians and patients should question [updated January 2018]. Available: https://choosingwiselycanada. org/family-medicine/ (accessed 2017 June 8).

9. Tigges S, Roberts DL, Vydareny KH, et al. Routine chest radiography in a primary care setting. Radiology 2004;233:575-8.

10. Mauri D, Kamposioras K, Proiskos A, et al. Old habits die hard: chest radiography for screening purposes in primary care. Am 7 Manag Care 2006;12:650-6.

11. Chest $x$-ray. Toronto: Ministry of Health and Long-Term Care. Available: www.health.gov.on.ca/en/pro/programs/phys_services/docs/chest_x_ray_is_ ea_en.pdf (accessed 2017 Jan. 2).

12. Bhatia RS, Bouck Z, Ivers NM, et al. Electrocardiograms in low-risk patients undergoing an annual health examination. 7AMA Intern Med 2017;177: 1326-33.

13. Kiran T, Kopp A, Moineddin R, et al. Longitudinal evaluation of physician payment reform and team-based care for chronic disease management and prevention. CMA7 2015;187:E494-502.

14. Hutchison B, Glazier R. Ontario's primary care reforms have transformed the local care landscape, but a plan is needed for ongoing improvement. Health Aff (Millwood) 2013;32:695-703.

15. Ponka D. The periodic health examination in adults. CMA7 2014;186:1245.

16. Personal health visit. Toronto: Ministry of Health and Long-Term Care. Available: www.health.gov.on.ca/en/pro/programs/phys_services/docs/periodic_ health_visit_is_ea_en.pdf (accessed 2017 Apr. 24).

17. Referral guidelines: 2012 CAR Diagnostic Imaging Referral Guidelines - Sections C $E, F, \mathcal{F}$ and $K$. Ottawa: The Canadian Association of Radiologists. Available: https://na01.safelinks.protection.outlook.com/? url=https $\% 3 \mathrm{~A} \% 2 \mathrm{~F} \% 2 \mathrm{~F}$ car.ca\% 2Fpatient-care $\% 2$ Freferral-guidelines $\% 2 \mathrm{~F} \&$ data $=02 \% 7 \mathrm{C} 01 \% 7 \mathrm{CS}$ acha.Bhatia \%40wchospital.ca\%7C1b1bb0a8652a4f7c611f08d5a94b2e2c\%7C26033a94b 4704c0bae8b58ee1d2eea24\% 7C0\%7C1\% 7C636601062724147974\&sdata=R M2Ca9LNcaRaG19cZMIW0ppds36771duOky8efLK0H8\%3D\&reserved=0 (accessed 2017 June 12).

18. Physician services under the Health Insurance Act. Toronto: Ministry of Health and Long-Term Care; 2015 Oct 1. Available: www.health.gov.on.ca/en/pro/ programs/ohip/sob/ (accessed 2017 Jan. 17).

19. Implementation of 2012 Physicians Services Agreement - amendments to the schedule of benefits for physicians services - effective January 1, 2013. North York (ON): Ontario Ministry of Health and Long-Term Care; 2013. Available: www. health.gov.on.ca/en/pro/programs/ohip/bulletins/4000/bul4585.pdf (accessed 2017 June 8).

20. Krogsbøll LT, Jørgensen KJ, Larsen CG, et al. General health checks in adults for reducing morbidity and mortality from disease: Cochrane systematic review and meta-analysis. BM7 2012;345:e7191.

21. Rosenberg A, Agiro A, Gottlieb M, et al. Early trends among seven recommendations from the Choosing Wisely Campaign. FAMA Intern Med 2015;175:1913-20.

22. Colla $\mathrm{CH}$, Sequist TD, Rosenthal MB, et al. Use of non-indicated cardiac testing in low-risk patients: Choosing Wisely. BM7 Qual Saf 2015;24:149-53.

23. Kirkham KR, Wijeysundera DN, Pendrith C, et al. Preoperative testing before low-risk surgical procedures. CMA7 2015;187:E349-58.

24. Postal Code Conversion File Plus (PCCF+), reference guide. Ottawa: Statistics Canada; 2014 [updated release date 2017 Dec. 13]. Available: http://data.library.utoronto. $\mathrm{ca} /$ datapub/codebooks/cstdli/pccf_health/pccf6a1/82-F0086-XDB-2014v6a-eng. pdf (accessed 2017 Feb. 6).

25. Bonett DG. Confidence interval for a coefficient of quartile variation. Comput Stat Data Anal 2006;50:2953-7.

26. Wolfson DB. It's not all about the money. Philadelphia: ABIM Foundation; 2016 Nov. 30. Available: http://abimfoundation.org/news/letter-from-the-foundation/ its-not-all-about-the-money (accessed 2018 Mar. 20).

27. Merlo J, Chaix B, Ohlsson H, et al. A brief conceptual tutorial of multilevel analysis in social epidemiology: using measures of clustering in multilevel logistic regression to investigate contextual phenomena. 7 Epidemiol Community Health 2006;60:290-7.

28. Larsen K, Merlo J. Appropriate assessment of neighborhood effects on individual health: integrating random and fixed effects in multilevel logistic regression. Am 7 Epidemiol 2005;161:81-8.

29. Snijders TAB, Bosker RJ. Multilevel analysis: an introduction to basic and advanced multilevel modeling. 1st ed. Thousand Oaks (CA): Sage Publications; 1999

30. Kiernan K, Tao J, Gibbs P. Tips and strategies for mixed modelling with SAS/ STAT procedures. Paper 332-2012. Cary (NC): SAS Institute Inc.; 2012. Avail- 
able: http://support.sas.com/resources/papers/proceedings12/332-2012.pdf (accessed 2017 June 3).

31. Pendrith C, Bhatia M, Ivers NM, et al. Frequency of and variation in lowvalue care in primary care: a retrospective cohort study. CMAF Open 2017;5: E45-51.

32. Schwartz AL, Landon BE, Elshaug AG, et al. Measuring low-value care in Medicare. FAMA Intern Med 2014;174:1067-76.

33. Bhatia RS, Levinson W, Shortt S, et al. Measuring the effect of Choosing Wisely: an integrated framework to assess campaign impact on low-value care. BM7 Qual Saf 2015;24:523-31.

34. Lee L-F. Specification error in multinomial logit models: analysis of the omitted variable bias. 7 Econom 1982;20:197-209.

Affiliations: Women's College Hospital Institute for Health Systems Solutions and Virtual Care (Bouck, Ivers, Bhatia) and Department of Family and Community Medicine (Martin), Women's College Hospital; Choosing Wisely Canada (Bouck, Levinson, Bhatia); Institute for Clinical Evaluative Sciences (ICES) (Mecredy, Ivers, Glazier, Bhatia), Toronto, Ont.; Cumming School of Medicine (Pendrith), University of Calgary, Calgary, Alta.; Trillium Health Partners (Fine), Mississauga, Ont.; Institute for Health Care Policy Management and Evaluation (Martin, Tepper), University of Toronto; Department of Family and Community Medicine (Glazier), St. Michael's Hospital; Departments of Diagnostic Imaging (Fine), Family and Community Medicine (Glazier, Tepper) and Medicine (Levinson), University of Toronto, Toronto Ont.

Contributors: Zachary Bouck, Ciara Pendrith and Sacha Bhatia designed the study. Noah Ivers and Ben Fine contributed to the conception and design of the study. Zachary Bouck and Graham Mercredy conducted the analyses, overseen by Sacha Bhatia. All authors contributed significantly to the interpretation and framing of the study data. Zachary Bouck and
Sacha Bhatia drafted the manuscript. All authors revised it critically, gave final approval of the version to be published and agreed to be accountable for all aspects of the work.

Acknowledgements: Noah Ivers is supported by a New Investigator Award from the Canadian Institutes of Health Research and the Department of Family and Community Medicine at the University of Toronto. Richard Glazier is supported as a Clinician Scientist in the Department of Family and Community Medicine at St. Michael's Hospital and at the University of Toronto. Sacha Bhatia is supported by a Clinician Investigator Award from the Heart and Stroke Foundation of Canada and the F.M. Hill Chair in Health Systems Solutions at Women's College Hospital.

Disclaimer: This study was supported by the Institute for Clinical Evaluative Sciences (ICES), which is funded in part by an annual grant from the Ontario Ministry of Health and Long-Term Care (MOHLTC). The funders had no role in the design and conduct of the study; the collection, management, analysis or interpretation of the data; the preparation, review or approval of the manuscript; or the decision to submit the manuscript for publication. The opinions, results and conclusions reported in this paper are those of the authors and are independent from the funding sources. No endorsement by ICES or the Ontario MOHLTC is intended or should be inferred. Parts of this material are based on data and information compiled and provided by CIHI. However, the analyses, conclusions, opinions and statements expressed herein are those of the authors, and not necessarily those of CIHI.

Supplemental information: For reviewer comments and the original submission of this manuscript, please see www.cmajopen.ca/content/6/3/ E322/suppl/DC1. 